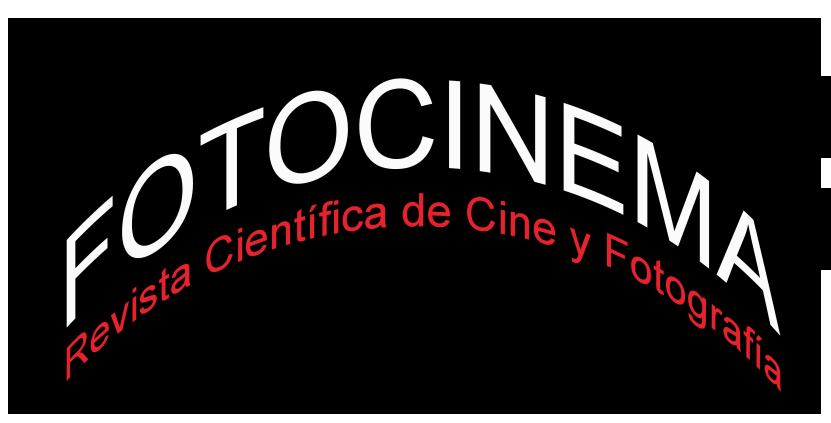

\title{
CASA ÁRBOL DEL TERROR: UN DISCURSO SOBRE LA MONSTRUOSIDAD Y LA INTERMEDIALIDAD EN LOS SIMPSON
}

\section{TREE-HOUSE OF HORROR: A DISCOURSE ABOUT MONSTROSITY AND INTERMEDIALITY IN THE SIMPSONS}

\author{
Ángel del Río Rodríguez \\ Universidad Autónoma de Barcelona, España \\ delriorodriguezangel@gmail.com
}

\section{Resumen:}

El monstruo es una criatura que persiste en nuestro imaginario colectivo. Se trata de una criatura que a la que constantemente acudimos para referenciarla y representarla, porque existe en el ser humano una extraña necesidad de remitir hacia él. Se trata de un ser capaz de dar vida a nuestros más oscuros deseos y de funcionar como la transgresión perfecta de los tabúes que silencia nuestra cultura. El monstruo es una figura imprescindible para transgredir los conceptos de normalidad que nos sujetan y nos someten. Es por esto que tenemos la necesidad de remitir a esa ambivalencia que nos plantea una y otra vez.

A lo largo de este artículo, ofreceremos una panorámica sobre los conceptos de intermedialidad y el discurso transversal que ofrece la serie animada Los Simpson; centrándonos, muy especialmente, en el modo que emplea para adaptar y reescribir a diferentes monstruos extraídos de la literatura y el cine, en sus capítulos de terror: La casa árbol del Terror (Treehouse of Horror).

\begin{abstract}
:
The monster is a creature that lingers in our collective imagination. It is a creature which constantly we go to reference and represent it, because there is in man, in us, a strange need to refer to him. It is a creature able to give life to our darkest desires and function as the perfect transgression of the taboos that silences our culture. The monster is a needed figure to transgress the concepts of normality that hold us and subject us. That is the reason why we need to refer to the constant ambivalence that raises again and again.

Throughout this article, we will offer an overview of the concepts of intermediality and transverse discourse that provides the animated series The Simpsons; focusing, in particular, in the way it uses to adapt different monsters and rewrite the extracted creatures from the literature and cinema, horror chapters: The treehouse of Terror.
\end{abstract}

Palabras clave: intermedialidad; monstruo; monstruosidad; adaptación.

Keywords: Intermediality; Monster; Monstrosity; Adaptation. 


\section{Definiendo al monstruo}

El monstruo es una criatura que persiste en nuestro imaginario colectivo. Se trata de un ser al que constantemente acudimos para referenciarlo y representarlo, porque existe en el ser humano una extraña necesidad de remitir hacia él. El monstruo siempre equivaldrá a una transgresión contra las directrices y contra la norma, su función es la de oponerse al sistema de pautas y de valores que ordenan nuestra realidad (en lo que refiere a nuestra organización social, como en lo que concierne al individual), porque su razón de ser es la de representar la anormalidad, lo extraño, lo no categorizable, lo ajeno y, por tanto, lo que se escapa de nuestro control. Tal y como advierte el antropólogo Claude Kappler (1980, p. 207): "Le monstre se définit par rapport à la norme, celle-ci étant un postulat du sens commun; la pensée n'attribue pas facilement au monstre une existence en soi alors qu'elle l'accorde spontanément à la norme”, una criatura que, como afirma Esteban Sánchez (1994, p. 314) se define por tratarse de "cualquier ser configurado de manera distinta (y desproporcionada) al orden regular y/o evolutivo de la naturaleza”.

Entendemos, por tanto, que el monstruo es una criatura que vulnera nuestras herramientas cognitivas, incapaz de ser sometido bajo ninguno de nuestros sistemas de clasificación, y que, por encima de todo, rehuirá toda determinación posible que tratemos de atribuirle. La naturaleza del monstruo dicta que es "un elemento que se opone a las estructuras que constituyen la vida. Se presentan siempre como una diferencia, una distinción en relación a la naturaleza" (Cortés, 1997, p. 18). De hecho, como advierte Cohen:

they are disturbing hybrids whose externally incoherent bodies resist attempts to include them in any systematic structuration. And so the monster is dangerous, a form suspended between forms that threatens to smash distinctions. (Cohen, 1996, p. 6).

El monstruo remite a aquello que no posibilita una determinación, puesto que habitualmente se construye como un ser incoherente, que escapa a todo tipo de racionalización y de identificación. Por ello, el monstruo ha sido una 
criatura recurrente en el imaginario colectivo del ser humano, cuando este se siente amenazado frente a un peligro.

Es habitual que se establezca una vinculación directa entre la criatura monstruosa y nuestro subconsciente, desde donde esta figura ficcional emerge como vía de escape para encarnar nuestros temores más atávicos, nuestros deseos más ocultos o como respuesta ante aquello que desconocemos. El monstruo, en tanto que criatura construida mediante unos parámetros totalmente imposibles, únicamente puede tener cabida en nuestra imaginación. Se estructura como un constructo ficcional que atenta contra los conceptos de normalidad, de orden y de norma. Es un ser configurado con la necesidad de remitir, siempre, a aquello inclasificable y caótico, tal y como sucede con las "choses qui apparoissent contre le cours de la Nature” (Kappler, 1980, p. 216). Esta dificultad de clasificación que posee el monstruo, y que lo define como principal rasgo constitutivo, es imprescindible para que podamos comprenderlo como una criatura que siempre va a tratar de funcionar como una amenaza frente a nuestros sistemas de valores. De hecho, mediante la construcción de esta serie de criaturas, tratamos de diseñar artefactos ficticios que permiten que otorguemos forma a nuestras principales amenazas, miedos y deseos:

los monstruos, maravillas, portentos, bestias, prodigios, signos y milagros sedimentan en ficciones frecuentemente definidas como reales ciertas amenazas que el hombre percibe o instituye. La condición misma del monstruo es ambigua: se finge su realidad tal vez para que no exista. [...] ante la emanación verdadera de lo terrible, el horror, lo ingobernable y lo caótico, el sujeto a punto de desplomarse en la incertidumbre absoluta desvía el impulso angustioso y lo diluye en bestias de ficción. (Herra, 1999, pp. 2324).

El monstruo equivale a nuestra capacidad imaginativa de proyectar y de construir unas criaturas ficticias que se encargarían de funcionar como: "artefactos salvadores, substitutos resistibles de la realidad irresistible" (Herra, 1999, p. 24). El monstruo, en tanto que artefacto construido por nosotros mismos, posee la facultad de liberar y de explicar nuestras 
emociones, poniéndolas de manifiesto mediante la figura de un ser que sea capaz de encarnarlas. Tal y como señala Jeffrey Jerome Cohen:

The monstrous body is pure culture. A construct and a projection, the monster exists only to be read: the monstrum is etymologically "that which reveals", "that which warms", a glyph that seeks a hierophant. Like a letter on the page, the monster signifies something other than itself: it is always a displacement, always inhabits the gap between the time of upheaval that created it and the moment into which it is received, to be born again. (Cohen 1996, p. 4).

Así pues, el monstruo va a constituirse como un método de comunicación y de representación del desasosiego humano. Como bien indica Kappler: "Le double mécanisme de projection des fantasmes et de re-création de la réalité s'illustre dans le monstre: celui-ci est une manière de voir à la fois ce qu'on ne voit pas ordinairement et ce qu'on voudrait voir: angoisse et désir s'y conjuguent” (Kappler, 1980, p. 259). El monstruo se encarga de mostrar aquello que permanece oculto dentro de nosotros (como pueden ser nuestros terrores, nuestros deseos o nuestras angustias) y que, mediante su constante revisión, podemos tratar de explicar o, mejor dicho, de explorar. Es cierto que, sobre todo, en la cultura popular y en la inmensa cantidad de productos culturales engendrados por los mass media (literatura, cine, videojuegos o cómics), se ha establecido una asociación, casi axiomática, que vincula al monstruo con nuestras pesadillas y con nuestros terrores (Bozzetto, 2001, p. 111). Aunque también es cierto que sería injusto limitar únicamente las capacidades representativas del monstruo a lo terrorífico y, por extensión, a nuestras pesadillas. Tal y como advierte Louis Vax advierte, al respecto:

[el monstruo] representa nuestras tendencias perversas y homicidas; tendencias que aspiran a gozar, liberadas, de una vida propia. En las narraciones fantásticas, monstruo y víctima simbolizan esta dicotomía de nuestro ser; nuestros deseos inconfesables y el horror que ellos nos inspiran. El más "allá" de lo fantástico en realidad está muy próximo; y cuando se revela, en los seres civilizados que pretendemos ser, una tendencia inaceptable para la razón, nos horrorizamos como si se tratara de algo tan ajeno a nosotros que creemos venido del más allá. Entonces traducimos ese 
escándalo "moral” en términos que expresan el escándalo "físico". La razón distinguía las cosas y subdividía el espacio, cede su lugar a la mentalidad mágica. El monstruo atraviesa los muros y nos alcanza donde quiera que estemos; nada más natural puesto que el monstruo está en nosotros. (Vax, 1973, p. 11).

En torno a esta idea, existe una marcada ambivalencia en lo que refiere a la construcción del ser monstruoso, manifestada a través de recurrentes y contrapuestos binomios, tales como temor/deseo, angustia/fascinación o rechazo/atracción, sobre los que nos basamos en el instante de atribuirle sus rasgos constitutivos (como por ejemplo los labios carnosos del vampiro y su semblante seductor o la imagen terrorífica de una difunta que oculta su rostro detrás de una larga y maltrecha melena). Cuando nos referimos al monstruo acudimos a una dicotomía entre el terror que puede entrañarpuesto que se trata de un ser que remite a lo desconocido y habitualmente a la muerte- y un extraño deseo o atracción, que nos suscita su enigmática figura, ajena a todo tipo de categorización, caótica (en resumen) y libre para actuar sin necesidad de acatar las normas que rigen nuestros sistemas culturales-. El monstruo encarna la vulnerabilidad del hombre desde estas dos vertientes: por un lado, como una figura que pretende transgredir nuestra realidad o exterminar nuestro mundo y a nosotros mismos. Es un ser que busca la destrucción, debido a su naturaleza anárquica; y, por otro lado, como una figura que libera la pulsión interna que mantenemos refrenada, que silenciamos bajo los reglas morales y éticas, pero que aun así poseemos. El monstruo, en tanto que criatura desenfrenada -en todos los aspectostiene la posibilidad de realizar todos sus deseos, sin privaciones ni limitaciones, porque el monstruo no puede ser condicionado. Es una criatura bestial, salvaje y acultural, no es posible someterlo a las reglas, porque se origina como respuesta a las mismas y porque proviene de los límites del entendimiento, por tanto, de los límites de la razón y la regulación. Como bien afirma Cohen:

The monster also attracts. The same creature who terrify and interdict can evoke potent escapist fantasies; the linking of monstrosity with the forbidden makes the monster all the more appealing as a temporary egress from 
constraint. [...] We distrust and loathe the monster at the same time we envy its freedom, and perhaps its sublime despair. (Cohen, 1996, pp. 16-17).

\subsection{La monstruosidad}

Tras observar qué define al monstruo, como criatura anómala, es imprescindible que tratemos de resumir qué entendemos por la monstruosidad, siguiendo la propuesta que diferentes teóricos han realizado sobre ella. Tal y como advierte Roman Gubern (1979, p. 39) la monstruosidad se define como: "una categoría de la anormalidad y la anormalidad [...] lo anormal inquieta y asusta, especialmente cuando se trata de la grave anormalidad que comúnmente llamamos monstruosidad”. Por su parte, Cortés advierte que:

lo monstruoso sería aquello que se enfrenta a las leyes de la normalidad. Unos monstruos traspasan las normas de la naturaleza (los aspectos físicos), otros las normas sociales y psicológicas, pero ambos se juntan, en el campo del significado, en la medida que, normalmente, lo físico simboliza y materializa lo moral. La dualidad bondad/maldad es una proyección sentimental del maniqueísmo bien/mal, [...] que también adquiere otras dicotomías como vida/muerte, instinto/razón, orden/desorden, antropomorfismo/bestialidad, naturaleza/ciencia o humano/mecánico. Lo monstruoso perturba (desde la transgresión hasta la agresión) las leyes, las normas, las prohibiciones de que la sociedad se ha dotado para su cohesión. (Cortés, 1997, p. 18).

La monstruosidad remitiría a la capacidad subversiva del monstruo, en tanto que es una criatura que viola los preceptos ordenadores y reguladores de nuestros sistemas de control. Se trata del efecto que caracteriza al monstruo y que subyace en él. La monstruosidad referiría a la fractura de todos nuestros principios reguladores de orden y estabilidad, que nos permiten conocer nuestro mundo y nuestra realidad, los cuales se han visto fragmentados por la irrupción de una criatura que no puede ser sometida ante ellos. Hablamos, por tanto, -en palabras de Foucault (2001, p. 63)- de una "transgresión, por consiguiente, de los límites naturales, transgresión de las clasificaciones, transgresión del marco, transgresión de la ley como marco: en la 
monstruosidad, en efecto, se trata de eso", de una transgresión que vulnera todos los niveles cognitivos y organizativos del ser humano.

El monstruo es una herramienta clave para lograr esa desestabilización que pretendemos alcanzar. Su no-clasificación, su indeterminación, su imposibilidad natural y, sobre todo, el efecto que provoca como agente del desorden y del caos son los rasgos monstruosos que presenta el monstruo y que, en consonancia, producen en nosotros un efecto de inseguridad y de temor, debido a que un elemento que no somos capaces de controlar y que nace como el necesario desorden se ha instaurado en nuestro mundo conocido. Como bien advierte Rosemary Jackson, sobre la función subversiva de la literatura fantástica y, por extensión, al monstruo -como criatura representativa-: "The fantastic traces the unsaid and the unseen of culture: that which has been silenced, made invisible, covered over and made 'absent'“ (Jackson, 1981, p. 4).

A continuación, tras haber establecido las líneas teóricas que consideramos imprescindibles para definir al monstruo, ofreceremos una breve panorámica sobre los conceptos de intermedialidad y, en relación con esto, del discurso transversal que ofrece la serie animada Los Simpson (Matt Groening). Posteriormente, nos centraremos en el modo que esta emplea para adaptar y para reescribir a los monstruos que juegan un papel destacado en dos de en sus capítulos de terror, titulados, Casa árbol del Terror (Treehouse of Horror), los cuales, como veremos, nos permitirán estrechar una vinculación directa entre la representación del monstruo en Los Simpson y su referente original. En nuestro análisis, nos detendremos en el análisis de dos ejemplos seleccionados, de la serie animada:

a) en primer lugar, el breve relato titulado: Bart Simpson's Dracula (perteneciente al capítulo Treehouse of Horror IV), en clara referencia al clásico vampiro de Bram Stoker, encarnado por el Sr. Burns.

b) en segundo lugar, he seleccionado el relato paródico: Nightmare on Evergreen Terrace (uno de los cuales pertenece al capítulo Treehouse of Horror VI), donde presenciamos una adaptación en clave humorística del film de Wes Craven, Nightmare on Elm Street (1984). 


\section{La ciudad de Springfield: El origen de un culto}

Tras una larga vida televisiva de más de veinte años, es muy probable que Los Simpson sea uno de los mayores fenómenos televisivos y del entretenimiento. Sin duda, se trata de una de las series más famosas y exitosas de la historia de la televisión. Esto es debido a la buena salud que, aún a día de hoy, mantiene su emisión. Las primeras andaduras de Homer, Bart y el resto de personajes tuvieron lugar en abril de 1987. Se trataba de unos cortos de animación, de aproximadamente unos minutos de duración, interpretados por una familia de color amarillo. A lo largo de los siguientes tres años y con un total de 48 episodios, se granjearon un lugar en la parrilla televisiva norteamericana. Fue en mayo de 1989 cuando Matt Groening, su creador, consiguió que estos cortometrajes se convirtieran en capítulos de veinte minutos, tal y como los conocemos hoy en día.

Los Simpson pasaron a ser en uno de los primeros programas de animación dedicados -no exclusivamente, pero sí con cierta predilección-a un público adulto. Con su particular modo de narrar el modelo de vida actual (haciendo hincapié en el norteamericano), y gracias a sus repetidos guiños a:

constantes e incansables citas de películas- tanto de cine de director como de cine mainstream o comercial), de programas de televisión, cultura musical (popular o de élite), y muchas otras manifestaciones provenientes tanto de la "alta" cultura literaria como de la cultura popular norteamericana (Martínez Ramos, 2010, p. 2).

De este particular modo obtienen como resultado la capacidad de entretener a un amplio y diverso público: desde niños y adolescentes, hasta a los propios académicos. En palabras del propio Groening: "Los Simpson es un programa que te recompensa si pones suficiente atención"1. Mediante su recurrente juego de intermedialidad, el espectador se halla ante una constante enumeración de símbolos y de referencias culturales que le son muy conocidos. De alguna manera, cuando nos sentamos a ver un capítulo de Los Simpson somos conscientes de que su creador realizará un amplio recorrido

\footnotetext{
${ }^{1}$ Fragmento extraído de: Groening, M. (2001): Los Simpson DVD, Primera temporada, 20th Century Fox.- (2002): Los Simpson DVD, Segunda temporada, 2oth Century Fox.
} 
por hechos culturales y sociales, que el espectador debe conocer para poder disfrutar por completo de la serie.

\section{Intermedialidad e intertextualidad}

Antes de avanzar más en las peculiaridades que ofrece la serie de Los Simpson, es imprescindible que definamos qué se entiende por intermedialidad y cuál es la relación que guarda con la serie de animación de Matt Groening.

Con el fin de comprender el funcionamiento de la intermedialidad, trataremos de observar brevemente cómo funciona la intertextualidad, cuya funcionalidad guarda cierta similitud. Para Genette el fenómeno de la intertextualidad tiene presencia cuando se establece una relación de copresencia entre dos o más textos (Genette, 1982, p. 8). Un ejemplo particular, que encajaría a la perfección con ello, sería el caso de la alusión, la cual la comprendemos como: "un enunciado cuya plena comprensión supone la percepción de su relación con otro enunciado al que remite necesariamente tal o cual de sus inflexiones" (Enríquez Veloso, 2012, p. 1753). Se trataría de un proceso en el cual establecemos: la relación de un texto con otros textos, o parte de un texto, siempre de manera consciente y con una marcada intención comunicativa. Tal y como advierte Casas: "la intertextualidad es, en efecto, un artificio indispensable en el proceso de emisión y de recepción lectora, sin el cual no sería posible construir el contenido explícito del texto" (Casas, 2014, p. 33).

En el caso de la intermedialidad no pondríamos el foco en una única dirección entre textos que vinculan una referencia, sino que trascenderíamos el ámbito literario con el que suele asociarse el concepto de intermedialidad, teniendo presencia en imágenes fílmicas, televisivas, textos literarios, pinturas o videojuegos, estableciendo un discurso conjunto entre los distintos medios, con el fin de narrar un motivo determinado, de volver a un tipo de personaje o a un relato (ya sean retomados desde su original o creados, de cero, basándose en un referente previo), sirviéndose de una serie 
de referencias culturales que construyen un mayor y rico texto, film, etc. Por tanto, entendemos que la intermedialidad, construida sobre la base de la intertextualidad (pero diferente a esta por los motivos señalados), alude a los constantes intercambios referenciales que se producen entre los diferentes medios de comunicación, como por ejemplo la literatura, el cine, las artes o la televisión, y observar el diálogo que se establece entre ellos, con el fin de analizar el impacto provocado. De esta manera:

El proceso por el que un relato, la narración de una historia, expresado en forma de texto literario, deviene, mediante sucesivas transformaciones en la estructura (enunciación, organización, y vertebración temporal), en el contenido narrativo y en la puesta en imágenes (supresiones, comprensiones, añadidos, desarrollos, descripciones visuales, dialoguizaciones, sumarios, unificaciones o sustituciones), en otro relato muy similar expresado en forma de texto fílmico. (De Felipe y Gómez, 2008, p. 17)

Este será el medio empleado para lograr la copresencia de elementos de diversos orígenes (literatura, cine, artes, televisión, videojuegos) dentro del nuevo al que pretendamos adaptarlo y lograr así una mayor riqueza y profundidad. Como bien afirman Fernando de Felipe e Iván Gómez: "la adaptación es, hoy más que nunca, un fenómeno intermediático que debe estudiarse atendiendo a las diferentes plataformas y universos de referencia que suministran contenidos, temas y argumentos al cine” (2008: 16).

Una vez definidas, brevemente, las líneas teóricas que persigue la intermedialidad, analizaremos cómo se presenta la intermedialidad a través de la obra de Groening.

\section{Los Simpson: Reflejo de una sociedad posmoderna}

Groening nos introduce en la ciudad de Springfield, un lugar desmarcado en el mapa norteamericano -completamente ficcional- pero que podría representar cualquiera de las miles de ciudades norteamericanas que conocemos. Springfield posee los habituales espacios que reconocemos como propios de una ciudad típica (los hogares están organizados siguiendo las 
clásicas distribuciones norteamericanas de casa unifamiliar con garaje, tienen un colegio completamente caracterizado por miles de series y películas, el bar al que acuden los habituales vecinos, la parroquia del pueblo o el supermercado), que funcionan como mecanismo de deslocalización de cualquier ciudad norteamericana, puesto que forman parte del espacio ficcional habitual que acostumbra a verse reflejado, tanto en el cine como en la televisión. En este espacio, Groening nos presenta las vivencias de unos mil personajes (desde Homer y nuestros conocidos Bart, Lisa, Maggey y Marge; Apu y sus ocho bebés; Moe y su inseparable Barney; el malvado Sr. Burns; Disco Stue; el frustrado Krusty; el siempre presente Troy McClure; el adorable y a la vez siniestro Flanders; o el autoritario director de escuela, y anteriormente soldado en Zanzibar, Skinner). Cada uno de estos personajes representan las preocupaciones, frustraciones, miedos y sueños del hombre moderno.

Cabe destacar que -pese su longeva duración- existe otra curiosa cualidad que define a Los Simpson: no existe un constante flujo temporal. De esta manera, y pese a las más de veinte temporadas, Maggie aún no ha dejado de ser un bebé, Bart y Lisa aún van a la escuela primaria y el Sr. Burns aún no ha aprendido el apellido de Homer. Groening establece una atemporalidad recurrente, que únicamente se ve actualizada por la presencia de intertextos o temas actuales, que confluyen con la realidad extratextual, realizando, de este modo, una constante actualización de los motivos y personajes que aparecen en la serie de animación.

Mediante estos rasgos tan característicos que identifican a la serie, su creador logra que Los Simpson se defina como: "nowhere living at no time, and representing no specific family” (Flóki Björnsson, 2012, p. 11), pero -del mismo modo- que funcione como perfecta identificación de cualquiera de las familias de clase media norteamericanas.

\subsection{Casa Árbol del Terror: Episodios espaciales de Halloween}

A lo largo de las veinte temporadas que componen la serie, nos encontramos con unos capítulos titulados Casa Árbol del Terror (en inglés, Treehouse of Horror). Es el nombre empleado en Los Simpson para aludir a los episodios 
especiales de Halloween, presentados anualmente, a modo de particular celebración Simpson de tan señalada fecha para la cultura anglosajona. Suponen una tradición que viene repitiéndose desde su primera temporada y siempre coincide con la celebración de la festividad. El nombre Treehouse of Horror hace referencia a las clásicas historias de terror que eran narradas en las casetas de los árboles, donde se juntaban los niños para contarse cuentos los unos a los otros y sentir miedo. Treehouse of Horror pretende recoger el testigo de esos relatos de terror, para introducir elementos terroríficos e inquietantes en la serie y realizar, de este modo, su particular aportación para la noche de Halloween.

En estos capítulos especiales de Halloween, no encontraremos una continuidad argumental - con respecto a la trama que siguen los episodios habituales-, sino que veremos a los protagonistas y demás personajes de Los Simpson envueltos en historias de terror, especialmente de género fantástico o de ciencia ficción, provocando que asuman diferentes roles con respecto a los que nos tienen acostumbrados: Bart en uno de los episodios se convertirá en un chico mitad niño, mitad mosca, en clara referencia al clásico del cine de terror The Fly (Kurt Neumann, 1958); en otro de ellos, Marge y sus hermanas serán unas hambrientas brujas, devoradoras de niños; e, incluso, en uno de estos capítulos podremos ver cómo Homer encarna a un paródico King Kong, (Merian C. Cooper y Ernest B. Schoedsack, 1933).

Asimismo, estos episodios especiales de Halloween sirven como mecanismo paródico de gran cantidad de cintas de género fantástico (tales como Los Otros, Pesadilla en Elm Street, o Paranormal Activity) y de ciencia ficción (como por ejemplo La Mosca, Inteligencia Artificial, Starship Troopers, o E.T.). De la misma manera, podemos encontrarnos con la parodización de grandes obras de la literatura (como Drácula de Bram Stoker o El cuervo de Edgar Allan Poe), las cuales, inevitablemente, sufren su particular conversión -reescritas y reinterpretadas- a través de la óptica y el particular modo de representar Simpson.

A continuación, tras haber observado los métodos constructivos empleados por la serie Los Simpson, observaremos -mediante el análisis de dos de sus 
episodios- cuáles son las técnicas empleadas por su creador para establecer una intermedialidad entre diferentes productos culturales y su serie de animación.

\subsection{Bart Simpson's Dracula²}

El primero de los breves relatos que hemos seleccionado es el que lleva por nombre: Bart Simpson's Dracula, el cual como es más que evidente hace referencia a la obra literaria de Bram Stoker, Drácula (1897) y, por extensión, a la adaptación fílmica de Francis Ford-Coppola, de 1992, titulada de igual forma Bram Stoker's Dracula. En el capítulo, la familia Simpson ha sido invitada por el Sr. Burns (el jefe de Homer en la central nuclear de Springfield) para una peculiar cena que tendrá lugar en su casa de campo en Pensilvania - primer guiño humorístico del capítulo, en clara referencia al folklore vampírico, quien tradicionalmente procede de Transilvania- a medianoche. Allí, descubrirán que el Sr. Burns, además de ser un déspota magnate, también es un vampiro (y, a su vez, el causante de una serie de víctimas que asola Springfield). Tras el descubrimiento parcial de la naturaleza de Burns, Bart será transformado en vampiro y se unirá a la horda de vampiros de Burns. Por su parte, Lisa propondrá exterminar al magnate para, de este modo, acabar con la terrible amenaza que supone y, como resultado, para que Bart recupere su humanidad. Debemos indicar que esta idea parte de otro film de temática vampírica posmoderna titulada Lost Boys (Jóvenes Ocultos, Joel Schumacher, 1987), una cinta en la que se nos presenta a un grupo de vampiros adolescentes, completamente alienados de la sociedad y con la única voluntad de permanecer siendo jóvenes eternamente. En la película de Schumacher, los jóvenes no-muertos serán transformados por un vampiro decano, quien inoculando su sangre a los futuros vástagos, los convertirá en criaturas de la noche. Por extensión, el único medio de recuperar a alguien que ha sido vampirizado es mediante el exterminio del "vampiro originario/jefe". En Los Simpson, se establece una clarísima alusión al film de Schumacher cuando Lisa expone la posible

\footnotetext{
2. Relato perteneciente al capítulo Casa Árbol del Terror IV, quinto episodio de la quinta temporada. Emitido por primera vez el 28 de octubre de 1993 en Estados Unidos.
} 
solución del conflicto, como si de alguna manera ya conociese la relación vinculante, entre el vampiro originario y sus vástagos, del mismo modo que el propio film Lost Boys.

Centrándonos en Burns como vampiro, podemos observar que su primera aparición en escena supone un guiño a uno de los grandes clásicos del cine fantástico posmoderno, Drácula de Coppola (1992): el Sr Burns se presenta perfectamente caracterizado como Gary Oldman en el film (aparece en escena tras convertirse en humo, vestido con una camisola rojiza y el habitual peinado que lucía el vampiro de Coppola), estableciendo una asociación directa entre la película y la serie de animación. Por si eso fuera poco, el Burns vampiro posee también una sombra con autonomía propia que en ocasiones le sigue, mientras que en otras se dedica a juguetear con un yoyó. Si hasta este instante se podría hablar más de una referencia intertextual que de un recurso propio de la intermedialidad, es gracias a la incursión de Smithers (el ayudante personal del Sr. Burns) reconvertido en un muy acertado Renfield, como se potencia el efecto de referencias entre la obra de Stoker y la serie de animación. La inclusión del sirviente de Drácula, junto a su señor, alude directamente a la obra literaria, alejándolo del referente del cine. No obstante eso -como sucediese con el Sr. Burns- la caracterización de Renfield vuelve a remitir al film de Coppola. De esta manera, el episodio de Los Simpson funciona como un perfecto encaje entre la versión fílmica de Coppola y la obra narrativa de Stoker.

Empleando estos recursos es cómo comenzamos a observar un primer modo de reflejar cómo es representado el vampiro en diversos medios. El Drácula de Coppola resulta una libre adaptación del de Stoker, presentado como un monstruo capaz de amar y de padecer sentimientos puramente humanos, de los que carece el vampiro original del escritor irlandés. En cambio, Los Simpson retoman la codificación iconográfica que establece Coppola para representar al Sr. Burns, pero lejos de convertirlo en un monstruo con capacidad de enamorarse, Groening lo muestra como un ser desprovisto de sentimientos, en clara referencia al vampiro de Stoker. Se establece, así, un discurso en torno a la construcción del vampiro-Burns, extrayendo de ambas 
obras diversos rasgos que funcionarán para construirlo: por un lado la apariencia codificada por el cine, gracias a Coppola; y, por otro lado, la construcción interna del personaje, tomando las directrices establecidas por Stoker.

A lo largo del relato, la figura del vampiro es representada a través de diversos personajes que podríamos dividir en dos segmentos y, a su vez, en dos intertextos: en primer lugar, el Sr. Burns $\rightarrow$ Drácula; y en segundo lugar, Bart, Marge y el resto de vampiros $\rightarrow$ Lost Boys (1987, Joel Schumacher). En ambos casos el vampiro sufre una parodización constante, sus rasgos sobrenaturales se ven acentuados y llevados al extremo, de forma paródica: recordemos la aparición de Burns en la televisión, relamiendo unas gotas de sangre; la capa de Drácula, con el propio nombre escrito en ella, hallada en la escena del primer crimen; la compra del Sr. Burns del banco de sangre; la petición que les hace a la familia Simpson para que se limpien bien el cuello; el regreso momentáneo a la vida de Burns, después de que Homer le atraviese el corazón, con una estaca, para únicamente comunicarle que está despedido; o la dentadura postiza del abuelo Simpson, que posee los colmillos distintivos del vampiro.

Todos estos clichés ponen en constante referencia la imagen que el cine ha construido sobre la imagen del vampiro y, en especial, sobre sus rasgos constituyentes. El vampiro-Burns se ajusta a una larga tradición que ha codificado (por encima de todo) el cine, basándose en la obra de Stoker y que, película a película, han visto como los rasgos que definen al no-muerto han sido prolongados e incrementados.

Resulta interesante que la elección del Sr. Burns -quien, a su vez es un alegoría del capitalismo devorador- se emparente con la del vampiro, estableciendo una muy acertada vinculación entre el incontrolable e insaciable apetito del vampiro y el afán recaudatorio del Sr. Burns, como propietario de la central nuclear y, sin duda, el personaje más rico y poderoso de Springfield. Groening logra que su vampiro se enlace con las primeras representaciones de Drácula, propias de los años de la Gran Depresión, quien funcionaba, de manera simbólica, como: "un capitalista sanguinario, [que] 
abandona Transilavania tras exprimir a los campesinos locales" (Skal 2008, p. 194).

Por otro lado, y partiendo de los rasgos propios que caracterizan a la serie de Groening, en la historia se retoman recursos propios de la serie como son la descontextualización espacial y temporal, situándola en la ficticia ciudad de Springfield y en un acertado castillo de Pensilvania. A diferencia de lo que sucediese en la obra de Stoker, el vampiro-Burns no se desplaza a la gran ciudad para alimentarse de los vivos, sino que aguarda a sus huéspedes en su hogar. Resulta interesante observar que los personajes que funcionan como intertextos (por ejemplo el Sr. Burns o su ayudante Smithers) potencian la descontextualización temporal - debido a la caracterización de los personajes y al diseño de sus ropas-, en clara contraposición con la familia Simpson, que es presentada de manera habitual. Sumado a ello, no tenemos constancia de la central nuclear de Burns, ni tampoco de la ciudad moderna. Únicamente de un castillo antiguo. El espectador es llevado hacia un espacio totalmente nuevo, que se aleja de las coordenadas temporales que conocemos a través de la serie. Todos los personajes son extraídos de sus contextos habituales para emular y adaptar, tanto el relato de Stoker como el film de Schumacher, empleando pequeños guiños intermediales.

El vampiro representado en los Simpson posee todos sus rasgos físicos y metafísicos tradicionales. La figura del vampiro (planteada del mismo modo en los Drácula de Stoker y de Coppola, y en el film Lost Boys): es un devorador insaciable que aterroriza a los vivos, puede transformarse en bruma o murciélago y es una amenaza que subvierte la normalidad de Springfield y que, como es evidente, supone una transgresión en todos los niveles, incluso para su anómala realidad.

\subsection{Nightmare on Evergreen Ter. 3}

El segundo de los relatos que hemos seleccionado se titula: Nightmare on Evergreen Ter., segmento que funciona como alusión directa con el primero de los films de la terrorífica saga del recientemente fallecido Wes Crave, temporada. Emitido por primera vez el 29 de octubre de 1995 en Estados Unidos. 
Pesadilla en Elm Street (1984). Como sabemos, en la cinta de Craven, Freddy Krueger es un slasher fantástico que se introduce en los sueños de los jóvenes de Elm Street para acabar con sus vidas, y vengarse de quienes lo quemaron en vida. En el relato de los Simpson, Bart sufre una pesadilla en la que Willie (el encargado de mantenimiento del colegio de Springfield), como una perfecta encarnación de Freddy Krueger, trata de asesinarlo. Como sucede en el film original, la herida que Willie le ocasiona mientras Bart sueña persiste en la realidad. A la mañana siguiente, otros estudiantes del colegio cuentan los terroríficos ataques del siniestro bedel: Lisa ha sido podada, Nelson abrillantado y Martin, tras acabar fugazmente un examen y caer dormido, será estrangulado por Willie en sus sueños. Bart y Lisa cuentan lo sucedido a Marge, quien - sin demasiada resistencia- relata lo sucedido con Willie: el bedel se encontraba en la sala de máquinas, cuando tras una explosión, comienza a arder vivo. Rápidamente, acude solicitando ayuda a los padres de los niños de Springfield (quienes se encontraban reunidos en un aula), pero estos están discutiendo sobre otros asuntos y le piden que, por favor, espere su turno. Evidentemente, Willie fallece, pero antes de desaparecer (y de recogerse a sí mismo en un cubo) jura asesinar a todos los niños mientras duerman.

En la primera aparición en escena de Willie, como sucediera en el caso del vampiro-Burns, podemos observar una perfecta caracterización del personaje, respecto a la criatura de Wes Craven: posee su tradicional jersey a rayas (negras y rojas 4 ), el viejo sombrero y, pese a no estar armado con su habitual garra de cuchillas, Willie lleva consigo un rastrillo -herramienta apropiada para el bedel de la escuela. Además de ello, si por alguna otra cosa se caracteriza Krueger es, sin duda, por su cruel y ácido sentido del humor (recordemos que, en la saga, es habitual que tras cometer un asesinato, sentencie con una frase de humor). El Krueger simpsoniano retoma ese carácter tan propio del original y con frases como: -Encantado de rastrillarte (mientras acuchilla a Bart con su rastrillo); -Moris, tú mueres. Dominas una

4. Debemos indicar que el jersey que Freddy Krueger viste es en realidad a rayas verdes y rojas, puesto que son los colores que causan un mayor impacto en la retina humana y ese efecto es el que perseguía Wes Craven con su monstruo. 
lengua muerte, enfréntate a una viva (antes de asfixiar a Martin, con su lengua); -Cuando acabe contigo, te habré transformado en compos mortem (convertido en podadora); las cuales suponen, para el espectador que conoce bien el referente intermedial, un eficaz recurso empleado por Groenning para construir su personaje.

Como sucediera con el caso del vampiro, el slasher fantástico de Craven es parodiado y representado en clave de humor: comenzando por la propia elección de Willie como Krueger, siguiendo por su desatendida e ignorada muerte; las absurdas transformaciones del monstruo y sus vinculaciones constantes con el trabajo de bedel; o, como es evidente, en su reaparición al final del relato, tratando en vano de acabar con Bart y Lisa. No obstante eso, la representación y adaptación de Freddy Krueger es realmente interesante, ya que retoma los puntos característicos del monstruo y los aspectos subversivos que provoca la criatura fantástica: Willie aparece en los sueños de los niños y los asesina, tal y como hace Krueger. Willie y Krueger son la encarnación de los terrores nocturnos que padecemos. Sumado a ello, es una criatura con la capacidad de irrumpir en uno de nuestros lugares de seguridad, de reposo, donde no somos capaces de padecer ningún daño. El terror que producen Krueger y Willie está vinculado con la transgresión de este lugar de seguridad, con la imposibilidad de frenar los sueños y, por tanto, las pesadillas.

\section{Conclusiones}

En ambas representaciones hemos encontrado un mismo modo de proceder similar por parte de su creador, Groening. Los monstruos, a los que remite el autor de Los Simpsons, consiguen funcionar para el lector como un perfecto intertexto, al que el lector/espectador acude sin excesivos problemas. Evidentemente, las referencias a las que acude son grandes figuras del cine, de la literatura o, incluso de los mass media, hecho que socorre al lector/espectador a la hora de establecer los vínculos de referencialidad, para comprender adecuadamente qué pretende ser narrado en Los Simpsons o 
cuál es el uso de un determinado personaje. Detengámonos, brevemente, en los procedimientos que emplea Groenning:

a) por un lado, retoma los modos de codificación y de representación física de los personajes propios del cine, estableciendo así una referencia intertextual directa, para diseñar a los monstruos que dará vida en formato Simpson. Como hemos podido observar, tanto el vampiro-Burns como el slasher-Willie están diseñados basándose en los originales Drácula de Coppola y Krueger de Craven: a través de una indumentaria perfectamente mimetizada, de lo gestualidad propia de estos monstruos y, evidentemente, de sus capacidades identificables para el gran público. De la misma manera, los relatos narrados en los capítulos simpsonianos reproducen, con cierta fidelidad, los originales, volviendo a funcionar como un encaje perfecto para establecer un acertado diálogo entre el autor, la serie y el espectador, que permita la relectura de los relatos de terror.

b) por otro lado, el universo Simpson de Groening que, como bien sabemos, se basa en el humor, provoca un reajuste paródico de los monstruos representados -quienes, a pesar de no perder sus capacidades subversivas, anómalas y fantásticas que tanto les define- estarán sometidos a una reproducción irónica, completamente alejada de los contextos habituales en los que son representados y, por tanto, desprovistos del terror que deben provocarnos.

Groening logra esta inversión haciendo hincapié en la ridiculización y en la exageración de los clichés que definen al monstruo en cuestión (vampiro y slasher). Sumado a ello -y entendido como otro de los mecanismos intermediales que tanto emplea la serie de Groening-, sucederá que los personajes simpsonianos (encargados de dar vida a estas formas monstruosas) se apoderarán de los rasgos del monstruo original, de sus caracteres e incluso de los relatos que los envuelven y que los han convertido en insignias del terror, distorsionando muy adecuadamente todos estos elementos constituyentes, sometiéndolos a la transformación que implica el filtro-Simpson, lo cual les otorgará una nueva dimensión y un nuevo relato que narrar. Recordemos qué sucedía con Burns, quien ahora tenía una casa 
de campo en Pensilvania o que Willie, durante su muerte, permanece aguardando su turno para solicitar ayuda, mientras los padres de los alumnos de Springfield debaten acerca de trivialidades.

Gracias a la reelaboración de estos relatos, ampliamente conocidos por el espectador, Groening trata de reflejar cómo podrían leerse los cuentos tradicionales de terror, desde la óptica de despreocupación y desencanto que caracteriza a la sociedad posmoderna, donde los monstruos clásicos no funcionan de la misma manera. Pese a que continúan suponiendo una transgresión, para los niveles cognitivos y hermenéuticos de la realidad, han perdido su condición de seres terroríficos. La descontextualización espacial que los monstruos sufren, a la hora de vincularlos con un personaje de Los Simpson y de deslocalizarlos del relato tradicional de terror, genera una vuelta de tuerca en el motivo del vampiro y en el del slasher, persiguiendo la sátira y la ironía. A su vez, mediante a la reelaboración y la transformación de todos estos elementos, Groening logra establecer la imagen de una sociedad desencantada, en la que la presencia de un monstruo es un mal menor, respecto a las preocupaciones de la vida diaria. El monstruo se fragmenta como otro discurso más de la posmodernidad. De hecho, debemos reparar en que quien nos informa de la existencia del vampiro-Burns es el noticiario televisivo, lo cual se relaciona directamente con la comprensión de los mass media como fuente de cultura, y como otro discurso que tiene cabida, en la realidad posmoderna.

Tanto Krueger como el vampiro de Coppola son dos criaturas que podríamos catalogar de posmodernas. Recordemos que ambos aparecen en pleno apogeo de la era de la posmodernidad y que, como es evidente, ambos poseen rasgos propios del monstruo posmoderno: Drácula ya no es únicamente el sanguinario devorador de seres humanos (que construyó Stoker), ahora también es un vampiro con capacidad para amar y para enamorarse. Tal y como advierte Roas sobre la adaptación de Coppola:

Aunque el director estadounidense trató de presentarla como la auténtica adaptación de la novela de Stoker, la película incluye elementos nada fieles a ésta y, como afirma Martínez Lucena (2010, pp. 110-111), “deja de ser una 
novela de terror para pasar a ser una historia de amor: el que era un ser perverso en la historia original, pasa a tener esa doble cara y a justificar sus movimientos por la recuperación del amor de su esposa, que falleció suicidándose en la lejana Edad Media cuando creía que su marido había muerto, y que parece reencarnarse en Mina Harker(...) [De hecho,] Drácula muere en brazos de su amada, que, en una mezcla de reconocimiento de ese amor verdadero y de conmiseración, parece suscribir que el monstruo tiene su lado humano y positivo". [...] los vampiros se han incorporado a la vida humana corriente, lo que nos lleva a la última de las variantes posmodernas, en la que lo fantástico es naturalizado mediante un proceso que desemboca en lo maravilloso o que incluso instaura una nueva forma de realismo mágico. (Roas, 2012, pp. 449-450).

En el caso de Krueger, es cierto que se trata de un monstruo despiadado, pero logra establecer un vínculo con el espectador, ya sea debido a su ácido sentido del humor, a la ferocidad de sus acciones o, simplemente, por haberse convertido en una figura clave del terror posmoderno, erigiéndose como el principal protagonista del espectáculo. En torno a esta idea, debemos recordar que, desde hace unas décadas, vivimos en plena era de la monstruocultura 5 y, por este motivo, los monstruos han adquirido un mayor protagonismo, hecho que les permite forman parte del imaginario colectivo como personajes principales y característicos del cine de terror. Por ello, figuras como el vampiro de Coppola o el slasher de Craven han adquirido una mayor relevancia y, evidentemente, se han convertido en figuras claves de los mass media y de la cultura de masas anglosajona y, por extensión, global. Este motivo es una de las claves que explica el porqué de la presencia de estos monstruos en los capítulos terroríficos de Los Simpson. Ambas criaturas posmodernas vuelven a sufrir un nuevo giro, una nueva vuelta de tuerca, alejándolos de los contextos habituales en los que los encontramos y otorgándoles, en este nuevo escenario, una nueva personalidad, que termina por invertir y satirizar a los originales.

5. Aconsejamos la lectura de la obra de David Skal, Monster Show (2008), para profundizar en el término. 
El tratamiento paródico de los monstruos desactiva los efectos que debe producir el monstruo de terror, desautomatiza la transgresión y la subversión que tradicionalmente provocaban el efecto fantástico ${ }^{6}$, convirtiéndolos en elementos naturalizados. Como bien advierte Roas, respecto a la naturalización del monstruo:

Si lo convertimos -al monstruo- en una raza o especie más de las que pueblan el mundo, lo que hacemos con él es naturalizarlo, le extirpamos un rasgo que es común al resto de seres y fenómenos fantásticos: la excepcionalidad. Es decir, deja de estar fuera de la norma (Roas, 2012, p. 451).

Este procedimiento de actualización del monstruo provoca que el monstruo ya no suponga un conflicto (ni para el lector/espectador ni para los personajes), porque sería un personaje más. Esta situación se da en películas como Teen Wolf (Rod Daniel, 1985), en la cual un joven adolescente descubre que su verdadera naturaleza es la de un hombre-lobo. Lejos de suponer un problema, el chico (tras sufrir una transformación involuntariamente) es aceptado en la comunidad, y además, se convierte en la nueva sensación del instituto, del equipo de baloncesto y de la ciudad. Ya no importa que se trate de una criatura que se transforma en una bestia capaz de devorar a los hombres, se convierte en un fenómeno de atracción popular. En clave paródica funcionan también las míticas series televisivas que aparecieron sobre monstruos: Los Monsters y La familia Addams. La familia Monster estaba constituida por criaturas monstruosas que constituían una unidad familiar, mientras que los Addams, estaba compuesto por "seres humanos excéntricos y siniestros" (Skal 2005, p. 351) en los que no faltaba una monstruosa mano amputada, un cadavérico mayordomo o un ser cubierto en su totalidad de pelos. El hecho es que se trataba de monstruos perfectamente reconocibles (basados en las caracterizaciones que Hollywood estableció), pero que en lugar de mostrarse como monstruos se nos presentan como una familia norteamericana cualquiera, en clave sitcom. Mediante esta transformación conseguimos desvestir al monstruo de la amenaza que

\footnotetext{
${ }^{6}$ Recomendamos la consulta de David Roas, Tras los límites de lo real (2012), con el fin de comprender adecuadamente las referencias.
} 
debería suscitarnos, puesto que el humor funciona como aislante del miedo. Así, obtendríamos un nuevo mecanismo que funcionaría para naturalizar al ser monstruoso, mediante la anulación del terror, y para evocarlo hacia un nuevo tipo de géneros que, tradicionalmente, se antojaban impensables.

En Los Simpson, el particular tratamiento paródico del monstruo no vulnera la actitud crítica pretendida por Groening. Tanto el vampiro como el slasher son elementos que construyen el relato y, como resulta evidente por su construcción y representación, están perfectamente tomados de los films de Coppola y Craven, respetando la monstruosidad que producen. En cambio, la inclusión de Drácula y de Krueger, en la realidad simpsoniana, no producen el efecto que deben provocar. La problemática que pudiese acarrear la presencia de un monstruo queda diluida por la realidad mundana. En este sentido, se evidencia una fractura con los efectos monstruosos que estas criaturas producen y se refuerza una evidente quiebra con la tradición de las películas de terror. Otro de los criterios que definen a la posmodernidad.

En este sentido, el posicionamiento crítico del autor, frente a las estructuras y organizativas en sociedad y de cultura no se ven alteradas, se refuerza en contraposición con estas criaturas que remiten a la transgresión. Los monstruos no suponen un peligro frente a la realidad de una familia disfuncional, ni de la propia ciudad de Springfield, sino que su despreocupación y su desentendimiento (ante la irrupción de una criatura de este tipo) evidencian la relativización de las problemáticas sociales, tornándolas en entretenimiento. Lo real se traslada a los discursos emitidos por los medios de comunicación y todo aquello que no aparece en ellos no existe. Por tanto, no se traduce en una verdad objetiva ni puede resultar un problema.

Por otro lado, no debemos olvidar que la intención del creador de los Simpsons es la de narrar cuentos de terror, como sucedía en las casas árbol y que, por encima de todo, se trata de capítulos especiales de Halloween (pese al evidente proceso de parodización que sufren los relatos y sus respectivos monstruos). Todos sabemos qué implica Freddy Krueger y cuál es su historia, de la misma manera que somos conscientes de lo que supone la figura del 
vampiro, pero mantenemos la expectativa ante qué tipo de giro argumental puede ofrecernos su paso por los Simpson y cómo, de alguna manera, la intermedialidad nos volverá a narrar su historia desde otro punto de vista. Como bien advierte Busquier: "Una adaptación es otra adaptación a partir de la que existía, y que el respeto no consiste en repetir, sino en creer lo mismo, en tener el mismo espíritu. En querer contar eso de la misma manera y sin embargo contarlo de otra”. (de Felipe y Gómez, 2008, p. 46).

Por otro lado, cuando pretendemos analizar los medios de representación de la monstruosidad -comprendida tal y como Gubern (1979), Foucault (2001) y Cortés (1997) lo definen- debemos ser conscientes de que el efecto que provoca el monstruo siempre va a funcionar como:

una irregularidad natural tan extrema que, cuando aparece, pone en cuestión el derecho, que no logra funcionar. El derecho está obligado a interrogarse sobre sus propios fundamentos o bien sobre su propia práctica, o a callarse, a renunciar, a recurrir a otro sistema de referencia o, por último, a inventar una casuística. El monstruo es, en el fondo, la casuística necesaria que el desorden de la naturaleza exige en el derecho. (Foucault, 2001, p. 65).

La no-clasificación, el desorden y la subversión que supone la presencia del monstruo, estimulan en nosotros un efecto de inseguridad y de temor, debido a que un elemento que no somos capaces de controlar se ha instaurado en nuestro mundo conocido, desestabilizándolo por completo. En Los Simpson, tanto Willie como Burns, y el resto de vampiros, son criaturas que logran funcionar como desestabilizadores de la realidad intratextual. Son seres con capacidades sobrenaturales que transgreden todos los conceptos de ordenación cultural y que violan los preceptos naturales. Conservan su monstruosidad intacta. De hecho, el discurso que logra Groening empleando a estos monstruos - pese a la parodización que ambas criaturas monstruosas sufren- continúa funcionando: el vampiro-Burns no deja de ser una criatura no-muerta que vuelve a la vida para alimentarse de los vivos, del mismo modo que el slasher-Willie, quien tras fallecer vuelve al sueño de los niños para asesinarlos, manteniendo el caos que produce la presencia de estos seres que perturban la integridad de las leyes físicas y de las normas 
culturales y cognitivas que ordenan nuestra realidad. Groening es capaz de representar en clave paródica a los monstruos referenciados, pero decide prolongar el efecto que estos deben producir, porque provoca que sus monstruos mantengan y produzcan el mismo efecto subversivo que logran los originales.

En este sentido, la intermedialidad es capaz de establecer un diálogo entre la literatura, el cine y la televisión a la hora de poner en manifiesto qué debe suponer el monstruo y su presencia. Tanto en Drácula como en Nightmare on Elm Street los monstruos son seres que ponen en jaque el status quo y desestabilizan la realidad. Ambos casos construyen unas criaturas que son imposibles de categorizar y se desmarcan de los conceptos de ordenación, clasificación y comprensión humanas. A través de la intermedialidad podemos observar un discurso prolongado en el tiempo sobre qué debe de seguir produciéndonos el monstruo en sus constantes representaciones, contra qué debe atentar y qué supone la irrupción de una criatura anómala, sin cabida en los sistemas de ordenación y de comprensión humana.

El monstruo es una criatura a la que siempre volvemos a recurrir, para expresarnos sobre nuestra realidad, nuestras preocupaciones, nuestros deseos o fascinaciones. Por este motivo, mediante el uso de los mecanismos intermediales descritos, tendremos la posibilidad de retomar a los grandes personajes de la literatura, del cómic, del cine, etc. y de otorgarles una renovación en sus figuraciones, volviendo a hacer hincapié en ellos y, por extensión, en sus modos de representación, logrando así que estos monstruos vuelvan funcionen, tal y como el autor pretenda (actualizando sus rasgos terroríficos, satirizándolos o como método para exploración).

La intermedialidad nos permite que extraigamos a los monstruos fuera de sus contextos terroríficos habituales y que los situemos en otros ambientes, como medio para examinar su funcionalidad en un género que no les pertenece o en un escenario donde se encuentran descontextualizados. De este modo, extraer al monstruo de los contextos propios del terror, nos permite indagar en otros aspectos que le pueden ser vinculados y que, fuera de su hábitat, podemos explorar con mayor precisión. 
A pesar de ello y, sin duda, el efecto más relevante que logra el discurso que propone la intermedialidad es que todos estos monstruos permanezcan vivos. Tal y como advierte Casas, en el prólogo de la antología Las Mil Caras del Monstruo (2012):

La figura del monstruo, por lo tanto, sigue interpelándonos. Como lleva sucediendo desde sus inicios, su presencia -chocante, amenazadora, inquietante- trastorna las fronteras de lo comúnmente aceptado, haciendo que nosotros, los lectores nos interroguemos acerca de nuestra propia normalidad. Por diversas vías -en los casos más felices, distintas de las tradicionales- el monstruo sigue perturbándonos, pues al abrir brechas en las leyes de uniformidad que rigen nuestras sociedades (da igual en qué lugar o en qué momento nos encontremos) nos pone frente a frente con nuestros temores, deseos e inseguridades. (Casas 2012, p. 15).

\section{Referencias bibliográficas}

Bozzetto, R. (2001). Le Fantastique dans tous ses états. Publications de l'Université de Provence, Aix-en-Provence.

Calleja, S. (2005). Desdichados monstruos. La imagen deformante y grotesca de "el otro". Madrid: Ediciones de la Torre.

Casas, A. (2012). Las mil caras del monstruo; edición y prólogo de Ana Casas. Barcelona: Bracket Cultura.

Casas, A. (2014). El microrrelato y la reescritura fantástica del mito. En Roas, David y López Pellisa, Teresa. (2014) Visiones de lo fantástico en la cultura española (1970-2012). Málaga: E.D.A. Libros, Benalmádena.

Cohen, J. J. (1996). Monster Theory. University of Minnesota Press, Minneapolis

Cortés, J.M. (1997). Orden y Caos: un estudio cultural sobre lo monstruoso en las bellas artes. Barcelona: Anagrama.

De Felipe, F. y Gómez, I. (2008). Adaptación. Barcelona: Trípodos.

Enríquez Veloso, G. (2012). Intertextualidad en los Simpsons: Transgresión y ruptura formal. A Coruña: Universidade da Coruña.

Esteban Sánchez, M. (1994). De lo monstruoso o la ingeniaría genética de la imaginación. Contextos, XII/23-24. Págs. 313-336.

Flóki Björnsson, B. E. (2006). Postmodernism and the Simpsons. Háskóli Islands, Hugvísindadeild: Universitatis Islandiae.

Foucault, M.l (2001). Los Anormales: curso del Collège de France: 19741975. Madrid: Akal. 
Genette, G. (1982). Palimpsestes. La littérature au second degré. París: Seuil.

Groening, M. (2001). Los Simpson DVD, Primera temporada, 20th Century Fox.

Groening, M. (2002). Los Simpson DVD, Segunda temporada, 20th Century Fox.

Gubern, R. (1979). Las raíces del miedo: antología del cine de terror. Barcelona: Editorial Tusquets.

Herra, R. Á. (1999). Lo Monstruoso y lo Bello. San José (Costa Rica): Editorial de la Universidad de Costa Rica.

Jackson, R. (1981). Fantasy: The literature of subversion. Nueva York: New Accents

Kappler, C. (1980). Monstres, démons et merveilles a la fin du Moyen Age. París: Payot.

Martínez Ramos, D. E. (2010). El papel de la intertextualidad en la Lectura Crítica de un texto televisivo popular: El caso de los Simpsons. México: Universidad de Monterrey.

Roas, D. (2012). Mutaciones posmodernas: del vampiro depredador a la naturalización del monstruo. En Uberlândia-Mg, R. Let. \& Let. pp. 441-455.

Roas, D. (2013). El monstruo posmoderno: nuevas estrategias de la ficción fantástica de la revista Pasavento. Revista de Estudios Hispánicos, $\mathrm{n}^{\mathrm{o}} 1$.

Skal, D. J. (2008). Monster Show: Una historia cultural del horror. Madrid: Valdemar Intempestivos.

Vax, L. (1973). Arte y literatura fantásticas. Buenos Aires: Eudeba.

Cómo citar: Del Río Rodríguez, Á. (2017). Casa Árbol del Terror: un discurso sobre la monstruosidad y la intermedialidad en Los Simpson. Fotocinema. Revista científica de cine y fotografía, $\mathrm{n}^{\mathrm{o}}$ 14, pp. 205-231. Disponible: http://www.revistafotocinema.com/ 